\title{
Gastric adenocarcinoma in a patient re-infected with $H$. pylori after regression of MALT lymphoma with successful anti-H. pylori therapy and gastric resection: a case report Uday C Ghoshal*1, Debashish Guha2 ${ }^{2}$, Santu Bandyopadhyay3, Chiranjib Pal ${ }^{3}$, Srikanta Chakraborty 4 , Ujjala Ghoshal ${ }^{5}$, Tamal K Ghosh ${ }^{4}$, Bhaskar B Pal ${ }^{1}$ and Prabir K Banerjee ${ }^{1}$
}

Address: ${ }^{1}$ Department of Gastroenterology, Seth Sukhlal Karnani Memorial Hospital \& Institute of Postgraduate Medical Education and Research, 244, AJC Bose Road, Kolkata 700020, India, ${ }^{2}$ Department of Pathology, Seth Sukhlal Karnani Memorial Hospital \& Institute of Postgraduate Medical Education and Research, 244, AJC Bose Road, Kolkata 700020, India, ${ }^{3}$ Department of Cellular Immunology, Indian Institute of Chemical Biology, Kolkata, India, ${ }^{4}$ Science and Instrument center, Burdwan University, Burdwan, India and ${ }^{5}$ Department of Microbiology, NRS Medical College, Kolkata, India

E-mail: Uday C Ghoshal* - ghoshal@sgpgi.ac.in; Debashish Guha - sanjayguha@vsnl.net; Santu Bandyopadhyay - santu@cal2.vsnl.net.in; Chiranjib Pal - santu@cal2.vsnl.net.in; Srikanta Chakraborty - uday_ujjala@yahoo.com; Ujjala Ghoshal - ujjala@sgpgi.ac.in; Tamal K Ghosh - ghoshtamal@hotmail.com; Bhaskar B Pal - pkb@123.india.com; Prabir K Banerjee - pkb@123.india.com

*Corresponding author

Published: 14 March 2002

BMC Gastroenterology 2002, 2:6

This article is available from: http://www.biomedcentral.com/I47I-230X/2/6
Received: I October 200|

Accepted: 14 March 2002

(C) 2002 Ghoshal et al; licensee BioMed Central Ltd. Verbatim copying and redistribution of this article are permitted in any medium for any purpose, provided this notice is preserved along with the article's original URL.

\begin{abstract}
Background: Helicobacter pylori $(H$. pylori) has been etiologically linked with primary gastric lymphoma (PGL) and gastric carcinoma (GC). There are a few reports of occurrence of both diseases in the same patient with $H$. pylori infection.

Case presentation: We report a patient with $\mathrm{PGL}$ in whom the tumor regressed after surgical resection combined with eradication of $H$. pylori infection. However, he developed GC on follow up; this was temporally associated with recrudescence / re-infection of $H$. pylori. This is perhaps first report of such occurrence.

Conclusions: Possible cause and effect relationship between $H$. pylori infection and both PGL and $\mathrm{GC}$ is discussed. This case also documents a unique problem in management of PGL in tropical countries where re-infection with $H$. pylori is supposed to be high.
\end{abstract}

\section{Background}

Helicobacter pylori (H. pylori) has been etiologically linked with primary gastric lymphoma (PGL) and gastric carcinoma (GC) $[1,2]$. Evidences in favor of cause and effect relationship between $H$. pylori and PGL include: higher frequency of isolation in PGL than in controls [3]; development of the disease during long-term follow up of infected subjects [4]; regression after eradication of the organism [5]; and rapid recurrence following re-infection [6]. Therefore, all components of Koch's postulates for establishing cause and effect relationship between $H$. pylori and PGL are fulfilled [7]. Evidences in favor of etiological relationship between $H$. pylori and GC are somewhat incomplete. In most studies from developed countries $H$. $p y$ lori infection has been correlated with GC [8]; however, the data from developing world where $H$. pylori infection 
is more frequent and is acquired at an early age is somewhat contradictory $[9,10]$. There is no report of regression of GC after eradication of $H$. pylori. Recently, GC has been shown to develop in Mongolian gerbils after infection with $H$. pylori[11]. However, development of GC during follow up after fresh infection with $H$. pylori in humans has not been documented despite such report in PGL [4]. Accordingly we report a patient with PGL from India in whom surgical resection of the tumor combined with eradication of $H$. pylori was followed by regression of PGL. This patient developed metachronous GC associated with recrudescence / re-infection of $H$. pylori.

\section{Case presentation}

A 32-year-old man presented in May 1998 with epigastric pain of six months duration. The pain was constant without any relation to meal or radiation to back. He also complained of anorexia, weight loss, vomiting of copious amount of stale food without any bile for four months. Melena occurred once three months ago. There was no history of fever. He denied history of gastric cancer in his family. Physical examination revealed emaciation and pallor. There was no lymphadenopathy, hepatosplenomegaly and abdominal lump. Examination of throat did not reveal any abnormality.

Hemoglobin $=85 \mathrm{~g} / \mathrm{L}, \quad$ TLC $=6.7 \times 10^{9} / \mathrm{L}, \quad$ ESR $=78 \mathrm{~mm} / \mathrm{h}$. Chest radiograph was normal. Abdominal ultrasonogram did not reveal lymphadenopathy, hepatosplenomegaly or ascites. Upper gastrointestinal (UGI) endoscopy revealed hyperemic lower esophageal mucosa with multiple nonconfluent erosions; there was excessive food residue inside the lumen and multiple hypertrophied gastric folds with erosions over these. Pyloric orifice was narrow and endoscope could not be negotiated into the duodenum. Six biopsies taken from the hypertrophied folds revealed only chronic inflammatory infiltrate and no specific pathology. H. pylori was not detected on histologic examination of gastric biopsies. In house rapid urease test (RUT) was positive within 15 minutes and scanning electron microscopy (SEM, Hitachi S530, Japan) from biopsies obtained from relatively normal looking areas revealed multiple round cells (might be lymphocytes, figure 1A) but no $H$. pylori. Serum titer for IgG antibody against $H$. pylori using ELISA based commercially available kit (Monobind Incorporation, California) was positive (21 $\mathrm{IU} / \mathrm{ml}$ ). Lansoprazole was started. With a diagnosis of gastric outlet obstruction, surgery was done after 2 weeks. After exploring the abdomen by midline incision thickening and nodularity of antrum were detected. There was no regional lymphadenopathy. Partial gastrectomy, removal of peri-gastric lymph nodes, closure of resected end of the duodenum in double layers and end-to-side ante-grade retro-colic gastrojejunostomy were done. Postoperative course was uneventful. Histological examination of re-
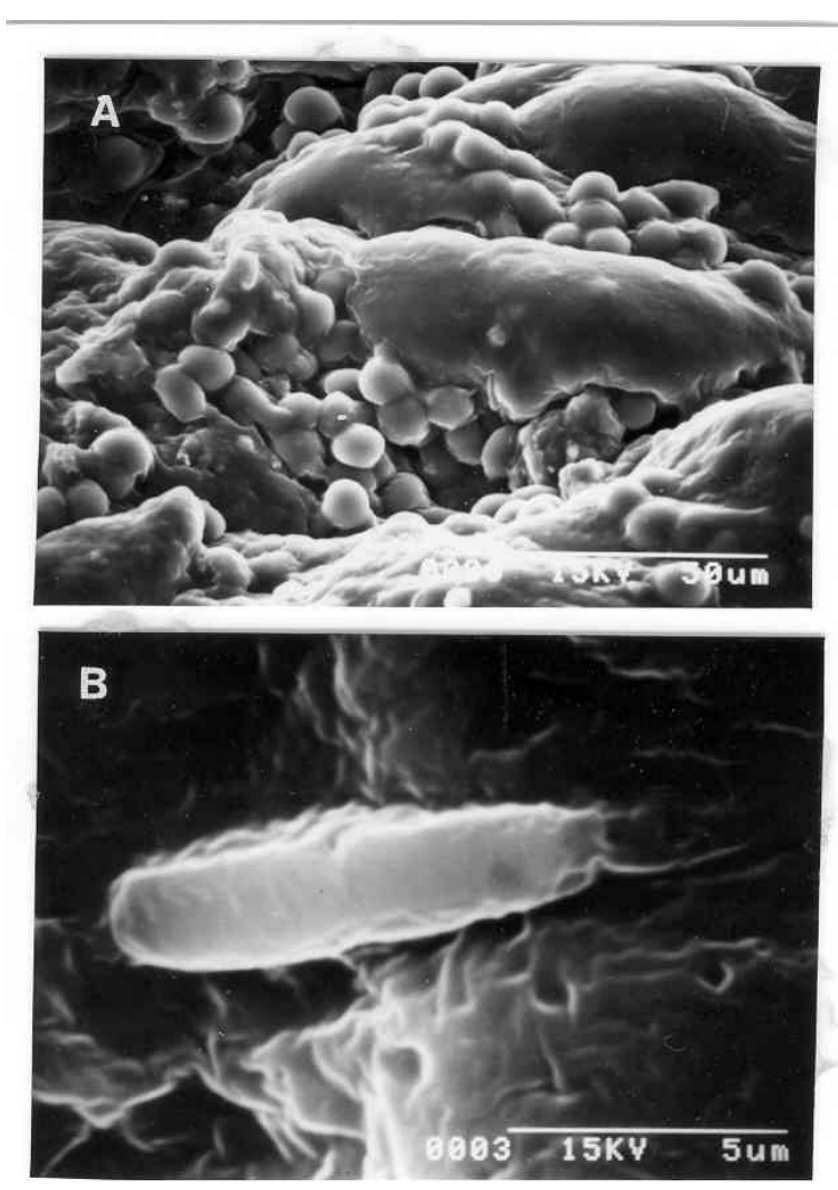

Figure I

(A) Scanning electron microphotograph of gastric mucosa at presentation showing multiple round cells (possibly lymphocytes) but No H. pylori $(\times 1000)$. (B) Scanning electron microphotograph of gastric mucosa during re-infection showing bacillus with polar flagella suggestive of $H$. pylori $(\times$ 8000).

sected specimen revealed transmural infiltration by mononuclear cells diffusely extending through muscularis mucosa into the submucosa without formation of lymphoid follicles, cellular atypia, abnormal mitotic figures (figure 2A) and lymphoepithelial lesions. On thorough histologic evaluation no evidence of synchronous GC was seen. Peri-gastric lymph nodes were not infiltrated by lymphoma. Bone marrow examination did not reveal any abnormality. On the basis of these morphological features a diagnosis of PGL (low-grade B cell lymphoma of MALT type by revised European-American classification) [12], stage I E: $\mathrm{I}_{1}$ (Musshoffs modification of Ann Arbor classification) [13] and $H$. pylori infection were made. Patient was treated with amoxycillin $1.5 \mathrm{~g} / \mathrm{d}$, omeprazole $40 \mathrm{mg} /$ $\mathrm{d}$ and tinidazole $1 \mathrm{~g} / \mathrm{d}$ for two weeks to eradicate the infection with $H$. pylori. UGI endoscopy repeated one 

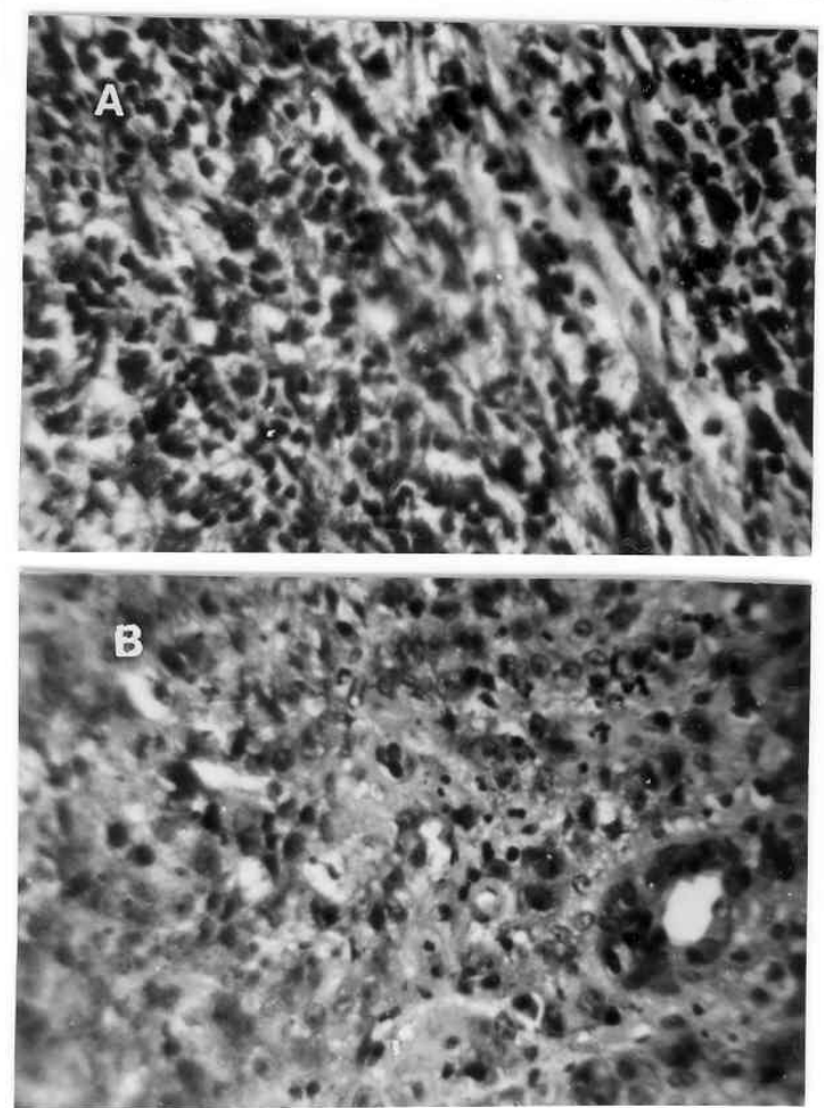

Figure 2

(A) Resected specimen of distal stomach showing diffuse infiltration by mononuclear cells without formation of lymphoid follicles with obvious cellular atypia and abnormal mitotic figures $(H \& E \times 275)$. (B) The high power view of recurrent gastric tumor showing pleomorphic cells, abnormal mitotic figures, mucin secretion and formation of gland at places diagnostic of adenocarcinoma $(\mathrm{H} \& \mathrm{E} \times 275)$.

month after completion of anti-H. pylori treatment revealed small sized stomach, no ulcer. RUT and Giemsa staining of biopsies obtained from proximal stomach were negative for $H$. pylori. However, a repeat UGI endoscopy done after six months revealed a benign-looking ulcer ( $1.5 \mathrm{~cm}$ in diameter) at gastrojejunostomy stoma. RUT and histology (Giemsa stain) on biopsies obtained from proximal stomach for $H$. pylori were still negative. Biopsy obtained by well technique from margin of the ulcer revealed chronic inflammatory infiltrate. Flow cytometry by standard technique [14] from these biopsies using antiCD 19 (B cell marker) and anti-CD3 (T cell marker) monoclonal antibodies revealed polyclonal infiltrate with 6.6\% CD 19 and 10.8\% CD3 bearing cells (figure 3). With a possibility of benign stomal ulcer patient was treated with lansoprazole $30 \mathrm{mg} / \mathrm{d}$ for 3 months. After this period

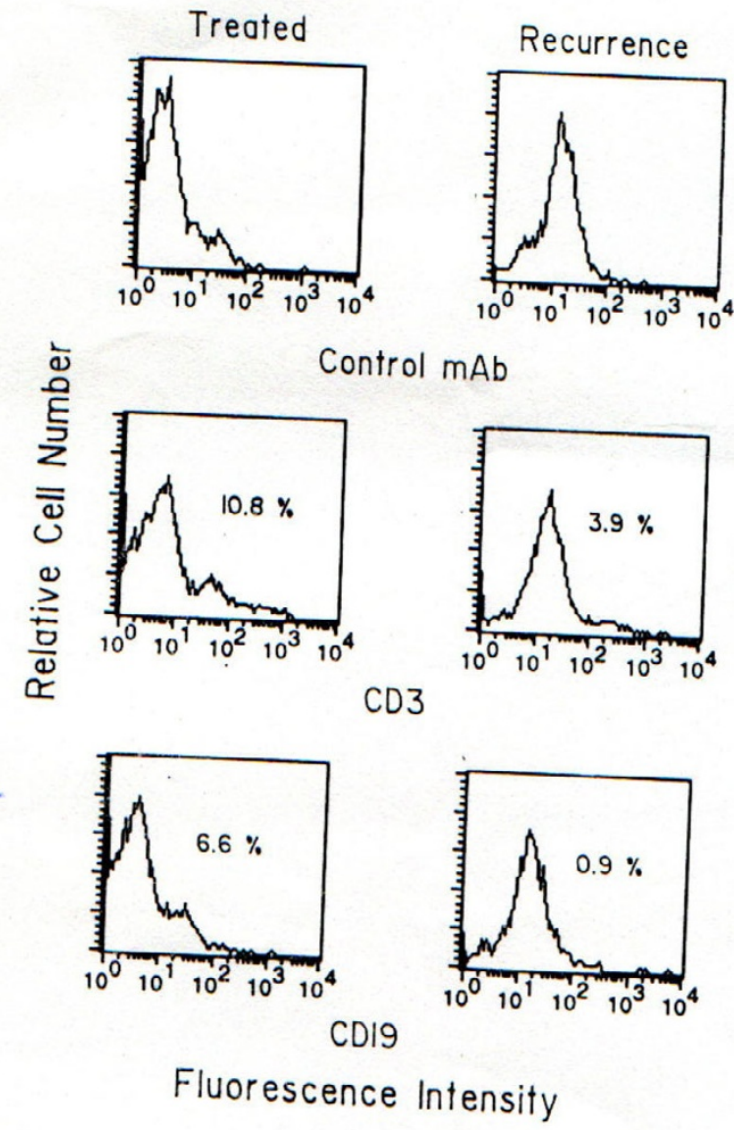

Figure 3

Flow cytometry was performed using FACS calibur (Becton Dickinson) and data were analyzed using Cell Quest program. One parameter histogram is shown.

of treatment, healing of the ulcer and absence of $H$. pylori infection were documented by UGI endoscopy and negative RUT respectively ( 2 weeks after stopping lansoprazole). On follow up during the next six months, he remained well with improved appetite and weight gain (35 to $46 \mathrm{~kg}$ ). He presented with recurrence of epigastric pain, anorexia and vomiting in August 1999. He had lost body weight (34 kg in August 1999). Examination revealed pallor, no peripheral lymphadenopathy and abdominal lump. UGI endoscopy: friable ulcerated growth involving most of stomach with reduced distensibility of the organ and patent gastrojejunostomy stoma. Since a possibility of recurrent PGL was considered, flow cytometry was done by standard technique [14] with biopsy from the tumor using anti-CD 19 (B cell marker) and anti-CD3 ( $\mathrm{T}$ cell marker) antibodies; it revealed a polyclonal lymphocytic infiltrate consisting of $0.9 \%$ CD 19 and 3.9\% CD3 bearing cells (figure 3). Biopsies obtained from rela- 
tively normal looking mucosa of stomach gave positive result to RUT. Histological examination revealed chronic gastritis but no intestinal metaplasia. SEM (Hitachi S530, Japan) with these biopsies revealed multiple bacilli suggestive of $H$. pylori (figure 1B). Histopathology of biopsy from margin of ulcers revealed multiple signet ring cells, cellular pleomorphism, mucin secretion, abnormal mitotic figures and gland formation at certain places (figure 2B). A diagnosis of GC and recrudescence / re-infection of H. pylori were made. Patient denied further treatment at this stage and left the hospital.

\section{Discussion and conclusion}

High index of suspicion is required for early diagnosis of PGL in developing countries. Endoscopic features of PGL may be very non-specific. Endoscopic findings like slight increase in thickness of gastric folds, multiple benign looking gastric ulcers or erosions [15] are too non-specific to suspect the disease unless endoscopist specifically looks for it. Endoscopic mucosal biopsy may miss the diagnosis [16] and may show only benign looking lymphocytic infiltrate as in the present case. Molecular diagnostic methods essential for confirming the diagnosis are not widely available in developing countries including ours. Early diagnosis is important, as eradication of $H$. $p y$ lori has been commonly shown to cause regression in an early stage of the disease [17]. H. pylori has been found more often in patients with PGL [3], chronic H. pylori infection progresses from polyclonal lymphocytic proliferation to PGL [4], and its eradication leads to regression [5]. Recurrence of PGL following re-infection with $H$. pylori following eradication has been documented in the literature [6]. Presence of $H$. pylori infection in our patient at presentation was evidenced by positive RUT (sensitivity $92 \%$, specificity $80 \%$ ) [18] and serology; absence of organism in SEM might be due to sampling error as similar phenomenon has been reported earlier in presence of gastric atrophy and intestinal metaplasia, both being common in chronic gastritis and malignancy [19]. Though, biopsy was obtained from endoscopically normal-looking mucosa, SEM showed round cell infiltration suggesting involvement by lymphoma. Absence of $H$. pylori in that area is quite expected. Diagnosis of PGL in our patient could be further confirmed by molecular biological methods before eradication of $H$. pylori. However, typical histology picture is quite diagnostic of PGL [20]. We could demonstrate clinical and histologic regression of the disease following surgical resection followed by eradication of H. pylori (documented by negative RUT and histology obtained from unresected proximal stomach). Flow cytometry of gastric mucosal biopsy documented polyclonal lymphocytic infiltrate confirming absence of residual lymphoma. Molecular evidences of the neoplasm may persist after treatment despite histological regression [21]. However, eradication of $H$. pylori removes growth stimulus for
PGL. Histological and molecular relapse in absence of reinfection with $H$. pylori are rare and transient [22].

Our patient developed GC on follow up after regression of PGL. This was temporally associated with re-infection with H. pylori. Positive RUT and demonstration of typical bacilli in SEM documented re-infection. Since we could not demonstrate a different genotype of $H$. pylori at the time of re-infection a possibility of recrudescence of earlier infection can not be entirely excluded though seems less likely. Development of intestinal metaplasia, a precursor of GC [23] and advanced cancer [11] has been reported after infection with $H$. pylori in Mongolian gerbils recently. This is perhaps the first report of development of GC following recrudescence / re-infection with $H$. pylori in human. We can not rule out a possibility of spontaneous development of GC. However, this seems less likely as in most cases of combined tumor reported earlier GC and PGL were synchronous in nature [24-29]. In a single series of 12 cases two developed metachronous tumor in both of whom GC preceded PGL [24]. In contrast, development of GC is expected to occur later in the course of $H$. pylori infection in patients with PGL [30]. The latter develops in the active phase of inflammation whereas the former in the pre-atrophic stage of gastritis [30]. In our patient resected specimen of PGL on thorough histologic examination did not reveal presence of synchronous GC. Therefore, as expected, GC in our patient developed later and was temporally associated with recrudescence / re-infection with $H$. pylori. Occurrence of metachronous GC after regression of PGL with eradication of $H$. pylori has been reported rarely $[31,32]$. Four cases of metachronous GC after regression of PGL with $H$. pylori eradication have been reported till date [31,32]. Development of GC in our patient was temporally associated with re-infection with H. pylori following regression of PGL. This is perhaps the first report of such an association. Considering several earlier studies [33,34], which suggested reduction in risk of GC following $H$. pylori eradication, temporal association of development of GC with recrudescence / re-infection with $H$. pylori in our patient is not difficult to explain. However, development of GC within a short period of time after fresh infection with $H$. pylori is somewhat odd as GC takes time to develop after infection with $H$. $p y$ lori[35]. A possibility of genetic or immunological predisposition can not be excluded. Further, since the patient was already chronically infected with $H$. pylori he might have been predisposed. Some workers have suggested a possibility of immunological containment of dysplastic epithelial cells by lymphocytic infiltrate [36]. Whether immunological imbalance resulting from regression of lymphocytic infiltrate could contribute to rapid development of GC, which got further triggered by re-infection or recrudescence of pre-existing infection with $H$. pylori remains an open question. Development of GC in this patient 
might be related to changes induced by many years of $H$. pylori related gastritis rather than a few months of re-infection. However, since there was a temporal relation with reinfection, it could also be related to progression of existing changes induced over many years by re-infection. This remains a conjecture.

In conclusion, we have shown regression of PGL after surgical resection combined with eradication of $H$. pylori and development of GC in association with reinfection with $H$. pylori in the present case. This may suggest the possibility of cause and effect relationship of both these malignancies to $H$. pylori. This case also highlights a unique problem in management of PGL in tropical countries where re-infection with $H$. pylori is supposed to be high [37].

\section{List of abbreviations \\ H. pylori: Helicobacter pylori;}

PGL: primary gastric lymphoma

GC: gastric carcinoma

TLC: total leukocyte count

ESR: erythrocyte sedimentation rate

UGI: upper gastrointestinal

RUT: rapid urease test

SEM: scanning electron microscopy

IgG: immunoglobulin G

ELISA: enzyme linked immunosorbent assay

IU: international unit

MALT: mucosa-associated lymphoid tissue

CD: cluster of differentiation

\section{Competing interests}

None declared

\section{Acknowledgements}

We thank relatives of the patient for giving us written consent for publishing the patient's details.

\section{References}

I. Bayerdorffer E, Neubauer A, Rudolph B, Thiede C, Lehn N, Eidt S, Stolte M: Regression of primary gastric lymphoma of mucosaassociated lymphoid tissue type after cure of Helicobacter pylori infection: MALT lymphoma study group. Lancet 1995, 345: $159 \mid-1594$
2. Eurogast study group: An international association between Helicobacter pylori infection and gastric cancer. Lancet 1993, 34 | : | 359- | 362

3. Parsonnet J, Hansen S, Rodriguez L, Gelb AB, Warnke RA, Jellum E, Orentreich N, Vogelman JH, Friedman GD: Helicobacter pylori infection and gastric lymphoma. N Engl | Med | 994, 330: | 267- | 27|

4. Zucca E, Bertoni F, Roggero E, Bosshard G, Cazzaniga G, Pedrinis E Biondi A, Cavalli F: Molecular analysis of progression from Helicobacter pylori-associated chronic gastritis to mucosa associated lymphoid lymphoma of stomach. N Engl J Med 1998, 338:804-810

5. Thiede C, Morgner A, Alpen B, Wundisch T, Herrmann J, Ritter M Ehninger G, Stolte M, Bayerdorffer E, Neubauer A: What role does Helicobacter pylori eradication play in gastric MALT and gastric MALT lymphoma? Gastroenterology 1997, I I 3:S6 I-S64

6. Cammarota G, Montalto M, Tursi A, Vecchio FM, Fedelli G, Gasbarrini $\mathrm{G}$ : Helicobacter pylori reinfection and rapid relapse of low grade B cell gastric lymphoma. Lancet 1995, 345: 192

7. Howden CW: Clinical expressions of Helicobacter pylori infection. Am J Med 1996, 100:275-345

8. Forman D: The prevalence of Helicobacter pylori infection in gastric cancer. Aliment Pharmacol Ther 1995, 9:71-6

9. Holcombe C: Helicobacter pylori: the African enigma. Gut 1992, 33:429-43।

10. Bhasin DK, Kakkar N, Sharma BC, Joshi K, Sachdev A, Vaiphei K, Singh K: Helicobacter pylori in gastric cancer in India. Tropical Gastroenterol 1999, 20:70-72

II. Watanabe T, Tada M, Nagai H, Sasaki S, Nakao M: Helicobacter pylori infection induces gastric cancer in mongolian gerbils. Gastroenterology 1998, I I 5:642-648

12. Harris NL, Jaffe ES, Stein H, et al: A revised European-American classification of lymphoid neoplasms: A proposal from international lymphoma study group. Blood | 994, 84: | 36 |- | 392

13. Morgner A, Bayerdorffer E, Neubauer A, Stolte M: Malignant tumours of stomach: Gastric mucosa-associated lymphoid tissue lymphoma and Helicobacter pylori. Gastroenterol Clin North Am 2000, 29:593-607

14. Saha A, Chakraborti G, Sen S, Bandyopadhyay S: Leishmania donovani parasites interact with gamma /delta ${ }^{+}$human peripheral blood $T$ cells and induce susceptibility to NK cell-mediated lysis. Scand J Immunol 1999, 50:588-595

15. Aoun JP, Moukarbel N, Khoury S: Endoscopic pattern of primary gastric MALT Iymphoma. J Med Liban I 998, 46(3): I 3 I- I 35

16. Suekane H, lida M, Kuwano Y, Kohrogia N, Yao T, Iwashita A, Fujshima M: Diagnosis of primary early gastric lymphoma: Usefulness of endoscopic mucosal resection for histologic evaluation. Cancer |993, 7 |(4): | 207-I213

17. Wotherspoon AC: Gastric MALT lymphoma and Helicobacter pylori. Yale J Biol Med. 1996, 69:61-68

18. Ghoshal UC, Ghosh TK, Ghoshal U, Shujaatullah F, Banerjee PK, Guha Mazumder DN: In-house rapid urease test kit and commercial kit: which is better? Indian J Gastroenterol 1999, I 8: 183

19. Karnes WE Jr, Samloff IM, Siurala M, Kekki M, Sipponen P, Kim SW, Walsh $\mathrm{JH}$ : Positive serum antibodies and negative tissue staining for Helicobacter pylori in subjects with atrophic gastritis. Gastroenterology 1991, I 01:167-174

20. Wotherspoon AC: Helicobacter pylori infection and gastric Iymphoma. In: British Medical Bulletin: Helicobacter infection 1998, 79. 85

21. Savio A, Franzin G, Wotherspoon AC, Zamboni G, Negrini R, Buffoli F, Diss TC, Pan L, Isaacson PG, Ospedale S, Orsola FBF: Diagnosis and post-treatment follow-up of Helicobacter pylori-positive gastric lymphoma of mucosa-associated lymphoid tissue: histology, polymerase chain reaction or both? Blood 1996, 87: $1255-1260$

22. Isaacson P, Diss TC, Wotherspoon AC, Barbazza R, Boni MD, Doglioni C: Long-term follow-up of gastric MALT lymphoma treated by eradication of Helicobacter pylori with antibiotics. Gastroenterology 1999, I 1 7:750-75 |

23. Hirayama F, Takagi S, Kushuhara H, Iwao E, Yokoyama Y, Ikeda Y: Induction of gastric ulcer and intestinal metaplasia in Mongolian gerbils infected with Helicobacter pylori. J Gastroenterol 1996, 3 1:755-757

24. Nakamura S, Aoyagi K, Iwanaga S, Yao T, Tsuneyoshi M, Fujishima M: Synchronous and metachronous primary gastric lymphoma 
and adenocarcinoma: a clinicopathological study of 12 patients. Cancer 1997, 79: 1077-1085

25. Goteri G, Ranaldi R, Rezai B, Baccarini MG, Bearzi I: Synchronous mucosa-associated lymphoid tissue lymphoma and adenocarcinoma of the stomach. Am J Surg Pathol 1997, 21:505-509

26. Hardman WJ 3rd, Gal AA, Pascal RR: Gastric adenocarcinoma and low-grade B-cell lymphoma of mucosa-associated lymphoid tissue. South Med J 1997, 90:426-430

27. Wotherspoon AC, Isaacson PG: Synchronous adenocarcinoma and low grade B-cell lymphoma of mucosa associated lymphoid tissue (MALT) of the stomach. Histopathology 1995, 27:325-331

28. Von Herbay A, Schreiter H, Rudi J: Simultaneous gastric adenocarcinoma and MALT-type lymphoma in Helicobacter pylori infection. Virchows Arch 1995, 427:445-450

29. Muller S, Seifert E, Stolte M: Simultaneous MALT-type lymphoma and early adenocarcinoma of the stomach associated with Helicobacter pylori gastritis. Z Gastroenterol 1999, 37:153157

30. Driessen A, Ectors N, Van Cutsem E, Penninckx F, Filez L, Pittaluga S, Delabie J, De Wolf-Peeters C, Geboes K: Different gastritis features are linked to different gastric neoplasms. Gastroenterol Clin Biol 1999, 23:747-753

3I. Morgner A, Miehike S, Stolte M, Neubauer A, Alpen B, Thiede C, Klann H, Hierlmeier FX, Ell C, Ehninger G, Bayerdorffer E: Development of early gastric cancer 4 and 5 years after complete remission of Helicobacter pylori-associated gastric low-grade marginal zone B-cell lymphoma of MALT type. World J Gastroenterol 200I, 7:248-253

32. Hasegawa N, Kato K, Yamada K, Morita K, Kuroiwa M, Ito H, Kamioka T, Matsuura T, Taguchi A, Ono K, Suzuki Y, Goto H: Early-stage gastric adenocarcinoma revealed after anti-Helicobacter pylori therapy of MALT Iymphoma. Gastrointest Endosc. 200I, 53:495

33. Uemura N, Okamoto S, Yamamoro S, Masuda H, Yamaguhi S, Mashiba H, Sasaki N, Taniyama K, Sumii K, Haruma K, Kajiyama G: Effect of Helicobacter pylori eradication on the background gastric mucosa in the patients after endoscopic mucosal resection of early gastric cancer. Gastroenterology 2000, I I 8:A502

34. Uemura N, Okamoto S: Effect of Helicobacter pylori eradication on subsequent development of cancer after endoscopic resection of early gastric cancer in Japan. Gastroenterol Clin North Am 2000, 29:819-827

35. Asaka M, Tadeka H, Sugiyama T, Kato M: What role does Helicobacter pylori play in gastric cancer? Gastroenterology 1997, I 1 3:S56-S60

36. Ioachim HL, Hajdu C, Giancotti FR, Dorsett B: Lymphoid proliferations and lymphomas associated with gastric metaplasia, dysplasia, and carcinoma. Hum Pathol 1999, 30:833-842

37. Guha Mazumder DN, Ghoshal UC: Epidemiology of Helicobacter pylori in India. Indian J Gastroenterol 1997, I6(SuppI I):S3-S5

\section{Pre-publication history}

The pre-publication history for this paper can be accessed here:

http://www.biomedcentral.com/1471-230X/2/6/prepub

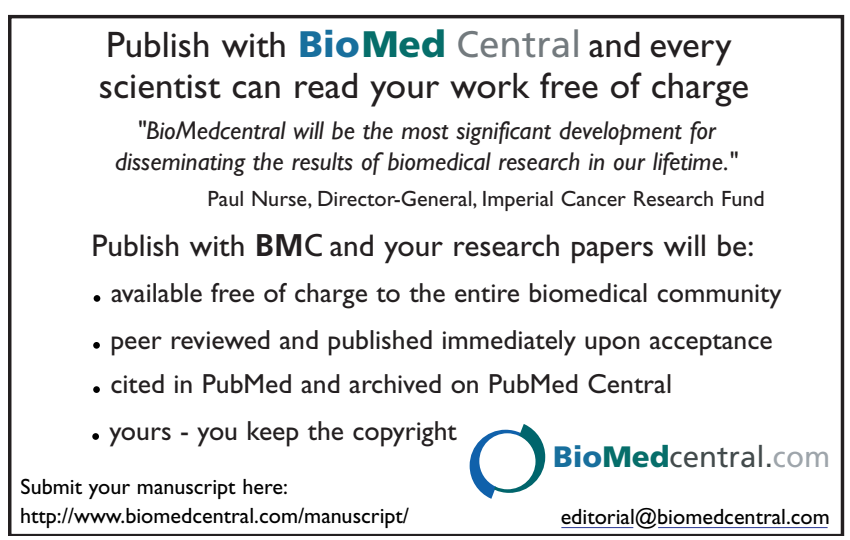

